\title{
Methods to estimate baseline creatinine and define acute kidney injury in lean Ugandan children with severe malaria: a prospective cohort study
}

Anthony Batte ${ }^{1}$, Michelle C. Starr², Andrew L. Schwaderer², Robert O. Opoka ${ }^{3}$, Ruth Namazzi ${ }^{3}$, Erika S. Phelps Nishiguchi ${ }^{4}$, John M. Ssenkusu ${ }^{5}$, Chandy C. John ${ }^{6}$ and Andrea L. Conroy ${ }^{6^{*}}$ (D)

\begin{abstract}
Background: Acute kidney injury (AKI) is increasingly recognized as a consequential clinical complication in children with severe malaria. However, approaches to estimate baseline creatinine (bSCr) are not standardized in this unique patient population. Prior to wide-spread utilization, bSCr estimation methods need to be evaluated in many populations, particularly in children from low-income countries.

Methods: We evaluated six methods to estimate bSCr in Ugandan children aged 6 months to 12 years of age in two cohorts of children with severe malaria $(n=1078)$ and healthy community children $(n=289)$. Using isotope dilution mass spectrometry (IDMS)-traceable creatinine measures from community children, we evaluated the bias, accuracy and precision of estimating bSCr using height-dependent and height-independent estimated glomerular filtration (eGFR) equations to back-calculate bSCr or estimating bSCr directly using published or population-specific norms.

Results: We compared methods to estimate bSCr in healthy community children against the IDMS-traceable SCr measure. The Pottel-age based equation, assuming a normal GFR of $120 \mathrm{~mL} / \mathrm{min}$ per $1.73 \mathrm{~m}^{2}$, was the more accurate method with minimal bias when compared to the Schwartz height-based equation. Using the different bSCr estimates, we demonstrated the prevalence of KDIGO-defined AKI in children with severe malaria ranged from 15.6-43.4\%. The lowest estimate was derived using population upper levels of normal and the highest estimate was derived using the mean GFR of the community children $\left(137 \mathrm{~mL} / \mathrm{min}\right.$ per $\left.1.73 \mathrm{~m}^{2}\right)$ to back-calculate the bSCr. Irrespective of approach, AKI was strongly associated with mortality with a step-wise increase in mortality across AKI stages ( $p<0.0001$ for all). AKI defined using the Pottel-age based equation to estimate bSCr showed the strongest relationship with mortality with a risk ratio of 5.13 (95\% Cl 3.03-8.68) adjusting for child age and sex.

(Continued on next page)
\end{abstract}

\footnotetext{
* Correspondence: conroya@iu.edu

${ }^{6}$ Department of Pediatrics, Ryan White Center for Pediatric Infectious Disease and Global Health, Indiana University School of Medicine, 1044 W. Walnut St., Indianapolis, IN 46202, USA

Full list of author information is available at the end of the article
}

C C The Author(s). 2020 Open Access This article is licensed under a Creative Commons Attribution 4.0 International License, which permits use, sharing, adaptation, distribution and reproduction in any medium or format, as long as you give appropriate credit to the original author(s) and the source, provide a link to the Creative Commons licence, and indicate if changes were made. The images or other third party material in this article are included in the article's Creative Commons licence, unless indicated otherwise in a credit line to the material. If material is not included in the article's Creative Commons licence and your intended use is not permitted by statutory regulation or exceeds the permitted use, you will need to obtain permission directly from the copyright holder. To view a copy of this licence, visit http://creativecommons.org/licenses/by/4.0/ The Creative Commons Public Domain Dedication waiver (http://creativecommons.org/publicdomain/zero/1.0/) applies to the data made available in this article, unless otherwise stated in a credit line to the data. 
(Continued from previous page)

Conclusions: We recommend using height-independent age-based approaches to estimate bSCr in hospitalized children in sub-Saharan Africa due to challenges in accurate height measurements and undernutrition which may impact bSCr estimates. In this population the Pottel-age based GFR estimating equation obtained comparable bSCr estimates to population-based estimates in healthy children.

Keywords: Acute kidney injury, Baseline creatinine, Schwartz, Pottel, Severe malaria, Sub-Saharan Africa, Methods, Mortality, Undernutrition, Pediatric

\section{Background}

Globally, 1.7 million people die from acute kidney injury (AKI) every year and $80 \%$ of deaths occur in low-and middle-income countries (LMIC) [1]. Mortality from AKI in children in sub-Saharan Africa is 34\% compared to a global average of $14 \%$ [2]. In contrast to highincome countries where the majority of AKI is hospitalacquired and managed in intensive care settings, the majority of AKI in LMIC is community-acquired [3]. As such, using admission creatinine to estimate baseline $\mathrm{SCr}$ (bSCr) likely leads to AKI under-recognition. In a study of Ugandan children with severe malaria with serial creatinine measures, half had their peak creatinine measured on admission [4].

AKI is diagnosed by increased serum creatinine or decreased urine output [5]. Accurate diagnosis of AKI relies on knowing bSCr which is ideally measured within 3 months of hospital admission. However, bSCr values are often unavailable in hospitalized patients, requiring $\mathrm{bSCr}$ estimation. A number of studies have evaluated approaches to estimate bSCr in pediatric populations in high-income countries [6-8]. The most commonly used approach is to assume a normal estimated glomerular filtration rate (eGFR) of $120 \mathrm{~mL} / \mathrm{min}$ per $1.73 \mathrm{~m}^{2}$ and use the Bedside Schwartz equation to back-calculate bSCr $[6,8-10]$. This approach has been used in large multinational studies [10], but has not been validated in LMIC settings where there are limited population-based estimates of creatinine in children.

Creatinine is affected by non-renal factors including muscle mass and nutritional status [11]. It is important to validate approaches to estimate bSCr in LMIC where undernutrition is more prevalent and lower estimated bSCr relative to height due to less muscle mass per body surface area may result in eGFR being overestimated [12]. Another challenge in using the bedside Schwartz equation to back-calculate estimated $\mathrm{bSCr}$ is the requirement for a height measurement. Height measurements are not always available in LMIC and it can be challenging to accurately measure height in the context of critical illness. As such, the development of validated height-independent approaches to estimate bSCr in LMIC would simplify AKI diagnosis. Recently, there have been efforts to measure creatinine and evaluate the burden of kidney disease in adults in sub-Saharan Africa [13-16], but data from pediatric populations are lacking [17].

In this study we evaluate six methods to estimate bSCr in two cohorts of Ugandan children. We evaluated the accuracy, bias and precision of methods to estimate bSCr compared to measured values in healthy children. In children with severe malaria, we evaluated the prevalence of AKI, and the relationship between AKI and mortality. We hypothesize that standard methods to define bSCr may lead to the underestimation of AKI in LMIC settings.

\section{Methods}

\section{Study populations}

We used two severe malaria cohorts that prospectively recruited children in Uganda between 2008 and 2017, and a population of healthy community children as controls (Fig. 1). All children with severe malaria had $P$. falciparum on blood smear or a positive rapid diagnostic test for Plasmodium falciparum HRP-2, and met World Health Organization criteria for severe malaria [18]. Severe malaria was defined according to WHO criteria: coma (Blantyre Coma Score $<3$ ), deep breathing, multiple convulsions, prostration, shock, abnormal bleeding, and jaundice; and laboratory indices of disease severity (severe anemia, hypoglycemia, hyperlactatemia, hyperparasitemia) (Fig. 1) [18]. Cohort 1 enrolled children meeting specific case definitions for cerebral malaria or severe malarial anemia [19]. Cohort 1 enrolled children aged 18 months to 12 years of age between 2008 and 2013 from Mulago National Referral Hospital in Kampala, Uganda [19]. Cohort 2 enrolled children with a broad range of severe malaria criteria: cerebral malaria, respiratory distress, multiple seizures, severe malarial anemia, or prostration. Cohort 2 enrolled children 6 months to 4 years of age between 2014 and 2017 from Mulago National Referral Hospital in Kampala or Jinja Regional Referral Hospital in Jinja, Uganda. Although children were enrolled in each study on the basis of specific severe malaria criteria, multiorgan dysfunction was common and children often presented with multiple severe malaria criteria (Fig. 1). Exclusion criteria included known chronic illness 


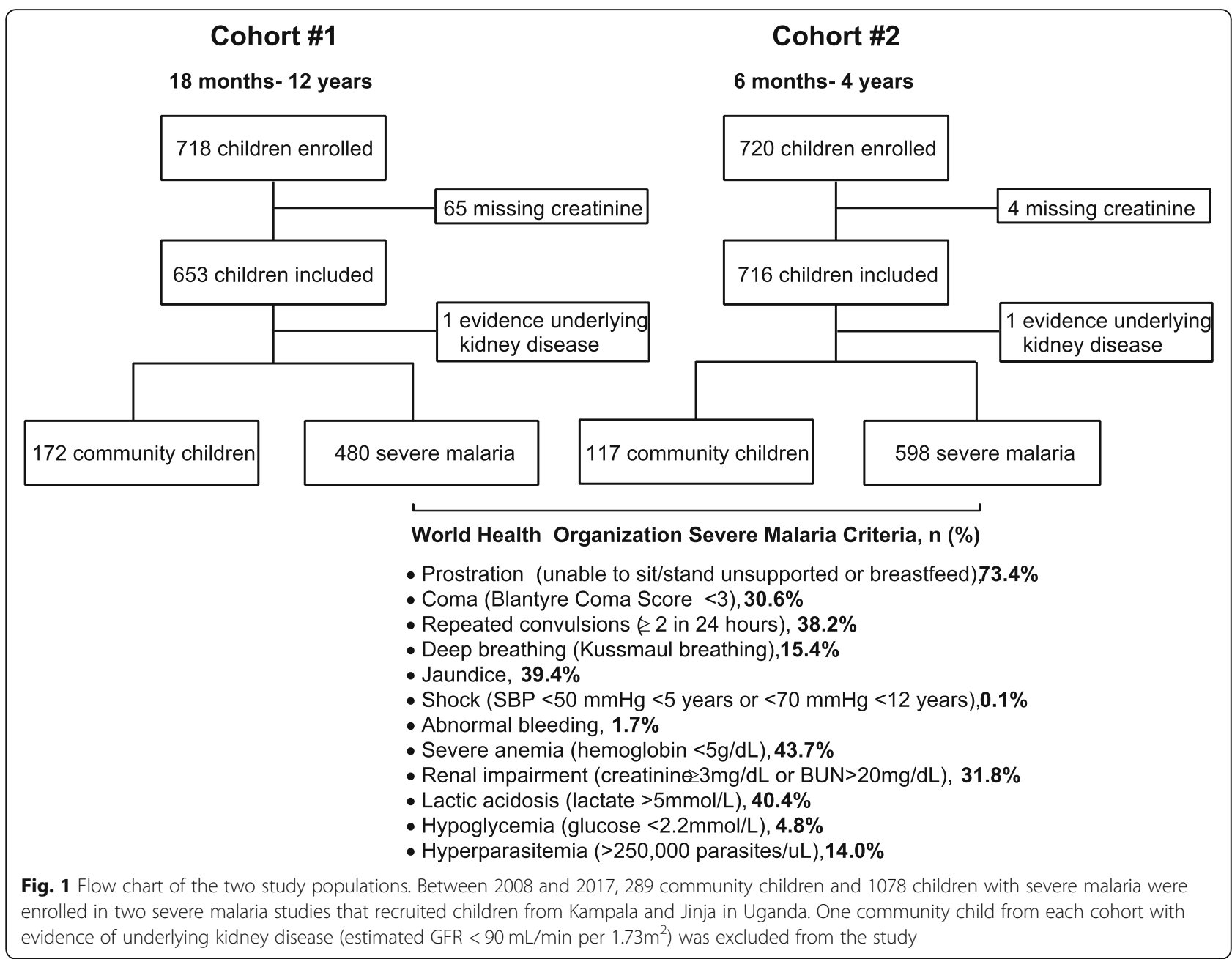

requiring medical care, known developmental delay, or history of coma, head trauma, hospitalization for malnutrition, or cerebral palsy. Additional exclusion criteria for the community children (CC) included any illness requiring medical care within the previous 4 weeks or major medical or neurologic abnormalities at screening physical examination, including a known history of kidney and urinary tract birth defects, or chronic renal disease. Community children with an eGFR $<90 \mathrm{~mL} / \mathrm{min}$ per $1.73 \mathrm{~m}^{2}$ calculated from the enrollment serum creatinine were excluded $(n=2)$. Community children in both studies were recruited from the nuclear family, extended family, or household area of children with severe malaria.

At enrollment all children had a history and physical exam and had blood drawn for clinical tests and EDTAanticoagulated plasma stored at $-80^{\circ} \mathrm{C}$ until testing. Children were weighed on a standardized electronic weighing scale. Height was measured using a stadiometer (recumbent) or a wall-mounted tape measure (standing height).
Recumbent height was taken on all children with SM at enrollment and standing at follow-up visits, while the community children were assessed standing for all visits. For cohort 2, the recumbent length was taken on all children across visits. Heights and weights were converted into $\mathrm{z}$ scores (height-for-age, weight-for-age, weightfor-height or bmi-for-age) based on 2006 World Health Organization (WHO) or 2007 WHO growth references based on age taking into consideration whether the measure was taken standing or recumbent $[20,21]$. Undernutrition was defined as a $\mathrm{z}$ score $<-2$ as follows: underweight (weight-for-age), stunting (height-for-age), or wasting (weight-forheight or BMI-for-age). Children were tested for sickle cell anemia as described [22]. A single blood pressure reading was taken on enrollment for all children using available instruments. As categorization of blood pressure based on standardized percentiles requires three independent measurements [23], we do not present data on hypertension in the population. 


\section{Quality review of height measurements}

In both cohorts serial heights were measured over followup. Children from cohort 1 had scheduled follow-up visits at 6,12 and 24 months, and children from cohort 2 had scheduled follow-up visits at 1 month and 12 months. Heights were also measured on unscheduled sick visits over follow-up. To identify within-subject height outliers, linear mixed effects models were used and standardized residuals were used to flag heights for further review [24, 25]. Models included height as the dependent variable and age and sex as fixed effects with a subject specific random intercept and slope. Cohort 1 flagged children with a standardized residual $>2$ or $<-2$ and cohort 2 used more stringent criteria of $>1$ or $<-1$ as more frequent height assessments were available for comparison. Heights flagged were independently reviewed for trend over time by two pediatricians (EPN and $\mathrm{AB}$ ) using height-for-age and weight-for-age $\mathrm{z}$ scores over time to identify outliers and make adjustments consistent with the child's individual growth trajectory ( $n=22$ adjustments, cohort $1 ; n=15$ adjustments, cohort 2). If heights were missing on admission, heights recorded at follow-up visits were used to interpolate the missing enrollment values $(n=5$, cohort 1 ; $n=7$, cohort 2). If height was missing and a follow-up height was not available (e.g. death), missing heights were estimated using WHO height-for-age reference curves stratified by sex $(n=24)[20,21]$. When the heights for both cohorts were plotted on WHO height-for-age reference curves, the curve for the population corresponded to the 10th percentile. In instances admission heights were missing without a follow-up height available, children were assigned a height based on the 10th percentile for the WHO curve $(n=19$, cohort $1 ; n=25$, cohort 2$)$. Admission heights when children were ill were noted as the most difficult heights to accurately measure.

\section{Assessing kidney function}

Creatinine was tested on cryopreserved enrollment samples using a Beckman Coulter AU680 using the modified Jaffe colorimetric method (Indiana University, Pathology Laboratory). Samples were sent on dry ice to the research laboratory at Indiana University, and then stored again at $-80 \mathrm{C}$ until sent to the Indiana University Pathology clinical laboratory for creatinine testing between 2012 and 2014 (cohort 1) and 2018 (cohort 2). Acute kidney injury was defined using the Kidney Disease: Improving Global Outcomes (KDIGO) criteria [5]. AKI was defined as a 1.5fold increase in creatinine over estimated baseline and was staged: stage $1,1.5-1.9 \mathrm{x}$ increase in creatinine over baseline; stage 2, 2.0-2.9x increase over baseline; stage 3, $\geq 3.0 \mathrm{x}$ increase over baseline. A single creatinine measure was available on admission and data on urine output were not collected. Dialysis was not available on site at the time the study was conducted.

\section{Methods of estimating $\mathrm{bSCr}$}

Six methods of estimating bSCr were evaluated (Fig. 2). First, we back-calculated estimated bSCr using an assumed eGFR value and height-dependent (Bedside Schwartz [26]) or height-independent (Pottel [27]) equations as shown below.

1. $\operatorname{bSCr}_{\mathrm{GFRSchwartz120}}\left(\mathrm{AKI}_{\text {Schwartz120}}\right)$ : back-calculate estimated bSCr using the Bedside Schwartz equation, where eGFR $=\left(0.413^{*}\right.$ height $) / \mathrm{SCr}$, assuming a normal GFR of $120 \mathrm{~mL} / \mathrm{min}$ per $1.73 \mathrm{~m}^{2}$ (heightdependent, reference).

2. $\mathrm{bSCr}_{\mathrm{GFRPottel120}}\left(\mathrm{AKI}_{\text {Pottel120 }}\right)$ : back-calculate estimated bSCr using the Pottel age-based equation, where eGFR $=107.3 /(\mathrm{SCr} / \mathrm{Q})$, assuming a normal GFR of $120 \mathrm{~mL} / \mathrm{min}$ per $1.73 \mathrm{~m}^{2}$ (height-independent). $Q=0.0270 *$ age +0.2329 .

3. $\mathrm{bSCr}_{\mathrm{GFRSchwartz137}}\left(\mathrm{AKI}_{\text {Schwartz137 }}\right)$ : back-calculate bSCr using the Bedside Schwartz equation, where eGFR $=\left(0.413^{*}\right.$ height $) / \mathrm{SCr}$, assuming a normal GFR of $137 \mathrm{~mL} / \mathrm{min}$ per $1.73 \mathrm{~m}^{2}$ corresponding to the population mean for healthy children.

We then used non-GFR based approaches to estimate bSCr directly.

4. bSCr $_{\text {upperlimit: }}$ Estimate bSCr using published upper limits of normal by age category (heightindependent) [28].

5. $\mathrm{bSCr}_{\text {heightCC: }}$ Estimate $\mathrm{bSCr}$ using linear regression models to estimate bSCr based on height-forcreatinine data from the community children, where $y=0.00276$ "height +0.03607 .

6. $\mathrm{bSCr}_{\text {ageCC}}$ : Estimate $\mathrm{bSCr}$ using linear regression models to estimate bSCr based on age-forcreatinine data from the community children, where $y=0.02058^{*}$ age +0.2199 .

Population-derived regression models were developed in healthy community children $(n=239)$ without sickle cell trait (HbAS, $n=40)$ or disease (HbSS, $n=1)$. See Additional File for Figure S1 showing the regression models for height- and age-based estimation of bSCr using the community children.

\section{Role of the funding source}

The funders had no role in the study design, analysis or decision to publish.

\section{Statistical analysis}

Data were analyzed using STATA v14.0 (StataCorp) and GraphPad Prism v7.03. Differences between continuous measures were analyzed using Student's t-test or oneway ANOVA, and differences in proportions were 


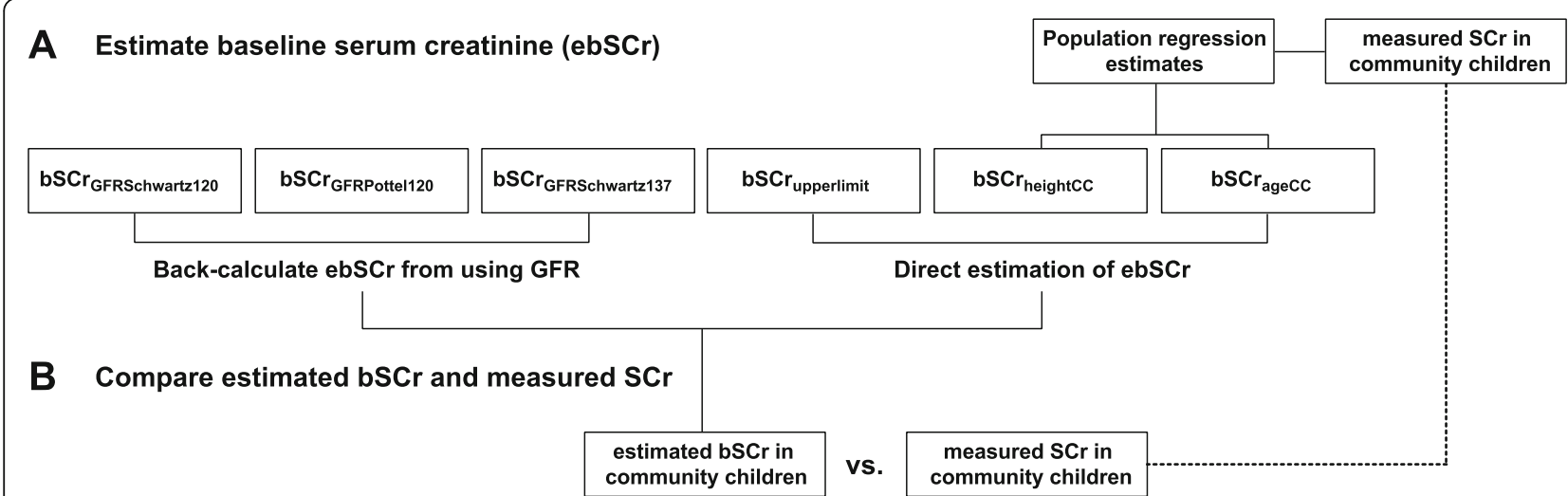

\section{Evaluate AKI prevalence in severe malaria}

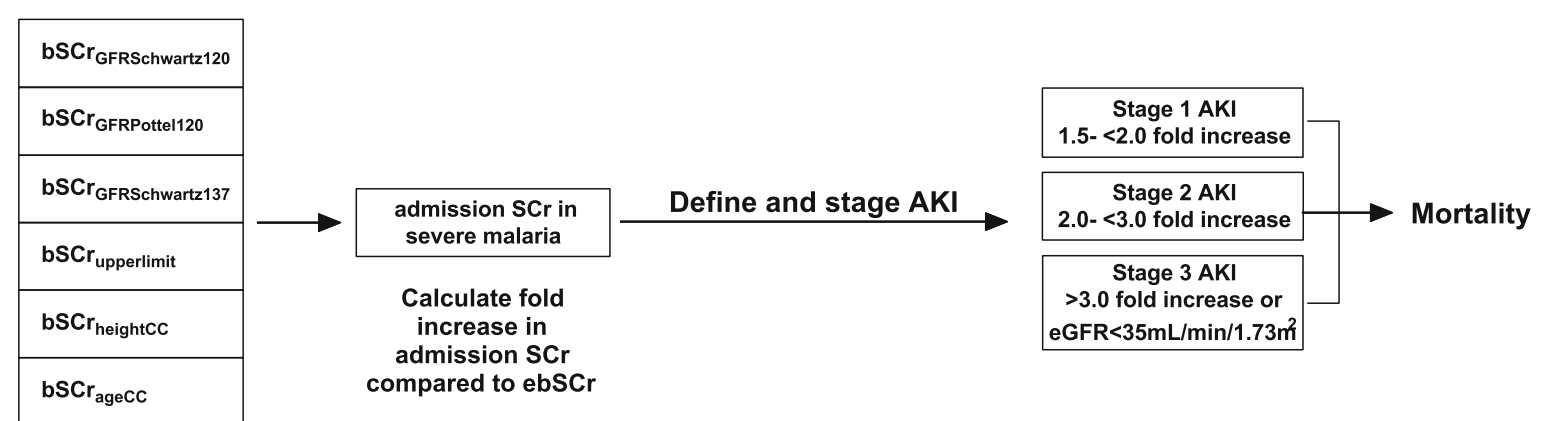

Fig. 2 Overview of approaches used to evaluate estimates of baseline serum creatinine. a Overview of GFR-based and direct SCr-based methods to estimate baseline serum creatinine (bSCr) in community children. Linear regression models using the height and age of community children were used for direct estimation of ebSCr heightcc and ebSCr$r_{\text {agecc. }} \mathbf{b}$ The estimated bSCr and measured SCr were compared in community children to evaluate the bias, precision and accuracy of methods. c AKI was defined in children with severe malaria using the different approaches to estimate bSCr, and the relationship between AKI and mortality was evaluated

analyzed using Pearson's Chi Square test or Fisher's exact test, as appropriate. To evaluate differences in the measured vs. estimated baseline creatinine in community children, Bland-Altman plots were generated. To compare the difference between the measured and estimated bSCr, we used a paired Wilcoxon signed rank test. Bias was represented by the total mean difference between estimated and measured creatinine, and compared to a hypothetical value of 0 using a one-sample t-test. Precision represents one standard deviation of the bias. Proportional bias was evaluated by testing if the slope of the linear regression model of the differences between estimated and measured creatinine against the average of estimated and measured creatinine differed from zero [29]. To evaluate accuracy, we compared the percentage of estimated bSCr values that fell within 10\% (p10) or $30 \%$ (p30) of the measured creatinine. Binomial exact confidence intervals were used to estimate the $95 \%$ confidence estimates for the AKI prevalence. To evaluate the relationship between AKI and mortality we used generalized linear models to estimate the risk ratio (RR) using binomial family and log link adjusting for age and sex. Model fit was assessed using Akaike information criterion (AIC) and Bayesian information criterion (BIC). Receiver operating characteristic (ROC) curves were also used to evaluate the relationship between AKI and mortality. A $p$ value $<0.05$ was considered significant.

\section{Results}

The present study prospectively enrolled children from 2008 to 2013 (Cohort \# 1, 18 months to 12 years of age) and 2014-2018 (Cohort \#2, 6 months to 4 years of age) (Fig. 1). The mean age (SD) of community children was 3.3 (1.9) years compared to 2.8 (1.6) years in children with severe malaria (Table 1). There was a sex difference in community children compared to children with severe malaria with $51.2 \%$ of community children female compared to $42.2 \%$ of children with severe malaria. There was no difference in height-for-age $\mathrm{z}$ scores between the community children and children with severe malaria. Children with severe malaria had lower weight-for-age and weightfor-height $\mathrm{z}$ scores and were more likely to be underweight or wasted compared to community children (Table 1). Overall, $24.7 \%$ of children were stunted, $17.7 \%$ underweight and $12.3 \%$ wasted. 
Table 1 Demographic characteristics of study population

\begin{tabular}{|c|c|c|c|c|c|}
\hline & \multicolumn{3}{|c|}{ Community children (CC) } & \multirow{2}{*}{$\begin{array}{l}\text { Severe Malaria } \\
(n=1078)\end{array}$} & \multirow{2}{*}{$\begin{array}{l}P \text { value } \\
\text { Combinec } \\
C C \text { vs. } \\
\text { Severe } \\
\text { Malaria }\end{array}$} \\
\hline & Cohort \#1 $(n=172)$ & Cohort \#2 $(n=117)$ & Combined $(n=289)$ & & \\
\hline Enrollment years & $2008-2013$ & $2014-2017$ & $2008-2017$ & $2008-2017$ & - \\
\hline \multicolumn{6}{|l|}{ Age, years } \\
\hline Mean (SD) & $4.01(2.03)$ & $2.22(1.02)$ & $3.28(1.91)$ & $2.83(1.62)$ & 0.0001 \\
\hline Median (IQR) & $3.59(2.61,4.62)$ & $2.21(1.39,3.09)$ & $3.00(2.06,3.92)$ & $2.50(1.75,3.47)$ & \\
\hline Min, Max & $1.55,11.44$ & $0.53,3.96$ & $0.53,11.44$ & $0.46,11.69$ & \\
\hline \multicolumn{6}{|l|}{ Age category, n(\%) } \\
\hline$<1$ & $0(0.0)$ & $18(15.4)$ & $18(6.2)$ & $74(6.9)$ & 0.001 \\
\hline $1-<2$ & $11(6.4)$ & $35(29.9)$ & $46(15.9)$ & $296(27.5)$ & \\
\hline $2-5$ & $128(74.4)$ & $64(54.7)$ & $192(66.4)$ & $609(56.5)$ & \\
\hline$>5$ & $33(19.2)$ & $0(0.0)$ & $33(11.4)$ & $99(9.2)$ & \\
\hline Sex, \% F & $94(54.7)$ & $55(47.0)$ & $149(51.2)$ & $455(42.2)$ & 0.004 \\
\hline Height, cm & $96.6(13.6)$ & $83.7(10.4)$ & $91.4(13.9)$ & $88.8(12.8)$ & 0.0032 \\
\hline Weight, kg & $14.7(4.4)$ & $11.6(2.6)$ & $13.5(4.1)$ & $12.0(3.6)$ & $<0.0001$ \\
\hline $\mathrm{BMI}, \mathrm{kg} / \mathrm{m}^{2}$ & $15.6(1.7)$ & $16.5(1.7)$ & $15.9(1.7)$ & $15.1(1.8)$ & $<0.0001$ \\
\hline Weight-for-age $e^{a}$ & $-0.82(0.98)$ & $-0.47(1.08)$ & $-0.68(1.04)$ & $-1.10(1.10)$ & $<0.0001$ \\
\hline Underweight ${ }^{a} \mathrm{n}(\%)$ & $21(12.5)$ & $9(7.7)$ & $30(10.5)$ & $209(19.6)$ & $<0.0001$ \\
\hline Height-for-age ${ }^{b}$ & $-1.25(1.13)$ & $-1.26(1.34)$ & $-1.25(1.22)$ & $-1.17(1.35)$ & 0.3602 \\
\hline Stunted, n (\%) & $43(25.0)$ & $36(30.8)$ & $79(27.3)$ & $259(24.1)$ & 0.250 \\
\hline Weight-for-height $<5^{c}$ & $-0.15(1.25)$ & $0.30(1.02)$ & $0.05(1.17)$ & $-0.65(1.32)$ & $<0.0001$ \\
\hline BMI-for-age $>5^{d}$ & $-0.30(0.84)$ & - & $-0.30(0.84)$ & $-0.80(1.43)$ & 0.0635 \\
\hline Wasted, n (\%) & $8(4.7)$ & $3(2.6)$ & $11(3.8)$ & $156(14.6)$ & $<0.0001$ \\
\hline Systolic BP & $94.1(10.2)$ & $98.5(11.7)$ & $95.9(11.1)$ & $95.9(13.0)$ & 0.9164 \\
\hline Diastolic BP & $60.9(10.6)$ & $59.1(9.8)$ & $60.2(10.4)$ & $56.9(12.1)$ & $<0.0001$ \\
\hline \multicolumn{6}{|l|}{ Enrollment SCr } \\
\hline Mean \pm SD & $0.31(0.08)$ & $0.26(0.07)$ & $0.29(0.08)$ & $0.48(0.48)$ & $<0.0001$ \\
\hline Median (IQR) & $0.30(0.24,0.35)$ & $0.25(0.20,0.30)$ & $0.28(0.23,0.33)$ & $0.38(0.29,0.49)$ & \\
\hline Min, Max ${ }^{a}$ & $0.19,0.56$ & $0.19,0.46$ & $0.19,1.0$ & $0.19,7.3$ & \\
\hline Enrollment eGFR, $\mathrm{ml} / \mathrm{min}$ per $1.73 \mathrm{~m}^{2}$ & $136.4(29.3)$ & $137.7(30.5)$ & $136.9(29.8)$ & $99.5(38.2)$ & $<0.0001$ \\
\hline
\end{tabular}

Data are presented as mean (SD) unless otherwise indicated. Undernutrition (weight-for-age $z$ score $<-2$ ), stunted (height-for-age $z$ score $<-2$ ), wasted (weightfor-height or bmi-for-age $z$ score $<-2$ ) according to WHO 2006 (age 0-5 years) and 2007 (5-12 years) reference standards

a Weight-for-age $z$ scores available for children < 10 years (Cohort \#1, CC $n=168, S M n=476$; Cohort \#2, CC $n=117, \mathrm{SM} n=591$; Combined, CC $n=285$;

SM, $n=1067$ )

${ }^{\mathrm{b}}$ Height-for-age z scores (Cohort \#1, CC $n=168, \mathrm{SM} n=479$; Cohort \#2, CC $n=117$, SM $n=598$; Combined, CC $n=289 ; \mathrm{SM}, n=1077$ )

${ }^{c}$ Weight-for-height $z$ scores available for children < 5 years (Cohort \#1, CC $n=139$, SM $n=388$; Cohort \#2, CC $n=117$, SM $n=591$; Combined, CC $n=256$;

$\mathrm{SM}, n=979$ )

${ }^{\mathrm{d} B M I-f o r-a g e ~ z ~ s c o r e s ~ a v a i l a b l e ~ f o r ~ c h i l d r e n ~} \geq 5$ years of age (Cohort \#1, CC $n=33, \mathrm{SM}=91$; Cohort \#2, CC $n=0, \mathrm{SM} n=0$; Combined, CC $n=33$; SM, $n=91$ )

'Wasted (Cohort \#1, CC $n=172, \mathrm{SM}=479$; Cohort \#2, CC $n=117, \mathrm{SM} n=591$; Combined, CC $n=289 ; \mathrm{SM}, n=1070$ )

Nutritional status affects creatinine levels and malnourished children tend to have lower creatinine levels and overestimate GFR [30]. When we calculated eGFR using measured creatinine levels and the bedside Schwartz equation in community children, the mean eGFR in community children was $137 \mathrm{~mL} / \mathrm{min}$ per $1.73 \mathrm{~m}^{2}$, which is higher than the assumed normal GFR of $120 \mathrm{~mL} / \mathrm{min}$ per $1.73 \mathrm{~m}^{2}$ that is used as assumed baseline in pediatric AKI research $[6,8,10]$.
The prevalence of sickle cell trait in Ugandan children is estimated to be $13.3 \%$ and sickle cell disease $0.7 \%$ [31]. There were $49(16.5 \%)$ community children with sickle cell trait (HbAS) and one (0.3\%) with sickle cell anemia (HbSS). There were no differences in eGFR or measured $\mathrm{SCr}$ in the community children based on the presence of sickle cell trait (mean (SD): HbAA, 0.29 (0.08) vs. HbAS, 0.30 (0.07), $p=0.207$; eGFR, HbAA, 137.7 (30.2) vs. HbAS, 132.5 (27.7), $p=0.265$ ). 
Approaches to estimate creatinine in community children To evaluate the most appropriate approach to estimate bSCr in this population (Fig. 2), we compared the measured and estimated baseline creatinine and eGFR in community children (Fig. 3). We evaluated the bias, precision and accuracy of the different approaches to estimate bSCr against the measured values in the community children using Bland-Altman analysis (Table 2, Fig. 4). When comparing the measured vs. estimated bSCr values using a paired Wilcoxon signed rank test, four methods had comparable measured and estimated bSCr values: the height $\left(\mathrm{bSCr} r_{\text {heightCC}}\right)$ and age-based $\left(\mathrm{bSCr}_{\text {ageCC}}\right)$ linear regression estimates as well as $\mathrm{bSCr}_{\mathrm{GFRS}} \mathrm{Shwartz137}$ and

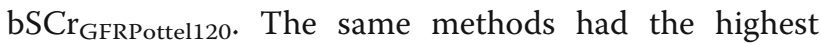
accuracy with the percentage values within $10 \%$ of the measured value ranging from 29 to $35 \%$ and the percentage of values within $30 \%$ of the measured value within $78-82 \%$ and three methods $\left(\mathrm{bSCr}_{\text {heightCC, }}\right.$ $\left.\mathrm{bSCr} \mathrm{r}_{\mathrm{ageCC}}, \mathrm{bSCr}_{\mathrm{GFRPottel120}}\right)$ did not show significant bias (Table 2, Fig. 4). Two approaches over-estimated bSCr: the upper limit of normal ( $\left.\mathrm{bSCr}_{\text {upperlimit }}\right)$, and

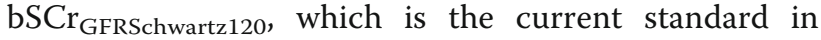
pediatric AKI research. The estimated bSCr using the mean of the community children ( $\mathrm{bSCr}_{\mathrm{GFRS}}$ chwartz137) was comparable to the measured value in the population, but underestimated bSCr in infants. All methods showed proportional bias in Bland-Altman analysis with a significant slope of the regression line comparing the difference and average between measured and estimated bSCr at higher creatinine values (Table 2, Fig. 4).

As there are physiological increases in GFR from birth to 2 years of age, using a single eGFR value across all ages may not be appropriate and age-related normative GFR values for children $<2$ years of age have been used in previous studies [8]. When eGFR was calculated using the Bedside Schwartz equation from bSCr $_{\text {GFRPottel120 or }}$ directly from estimated bSCr $\left(\mathrm{bSCr}_{\text {upperlimit }}, \mathrm{bSCr}_{\text {heightCC}}\right.$, $\left.\mathrm{bSCr}_{\text {ageCC}}\right)$ there was an increase in GFR across age groups with the lowest GFR in infants aged 6 months to $<1$ year of age (Fig. 3, Table 3). This trend is consistent with age-related increases in eGFR and $\mathrm{SCr}$ across age groups $(p<0.0001$, One-way ANOVA, Table 3, Fig. 3) with the largest difference observed in infants [32].

\section{AKI prevalence in children with severe malaria}

Using the different approaches to estimate bSCr we evaluated the prevalence of AKI on hospital admission in 1078 children with severe malaria (Figs. 2 and 5). AKI was based on a single admission creatinine and the six estimated bSCr values. AKI prevalence ranged from 15.6-43.4\% (Fig. 5a, Additional file 1, Table S1). The majority of AKI was stage 1 with staging estimates ranging from: 7.7-24.3\% Stage 1, 3.2-11.8\% Stage 2, and 4.7-7.3\% Stage 3 (Fig. 5a, Additional file 1, Table S1). The prevalence of AKI with the three approaches showing the best performance in estimating $\mathrm{bSCr}$ in the

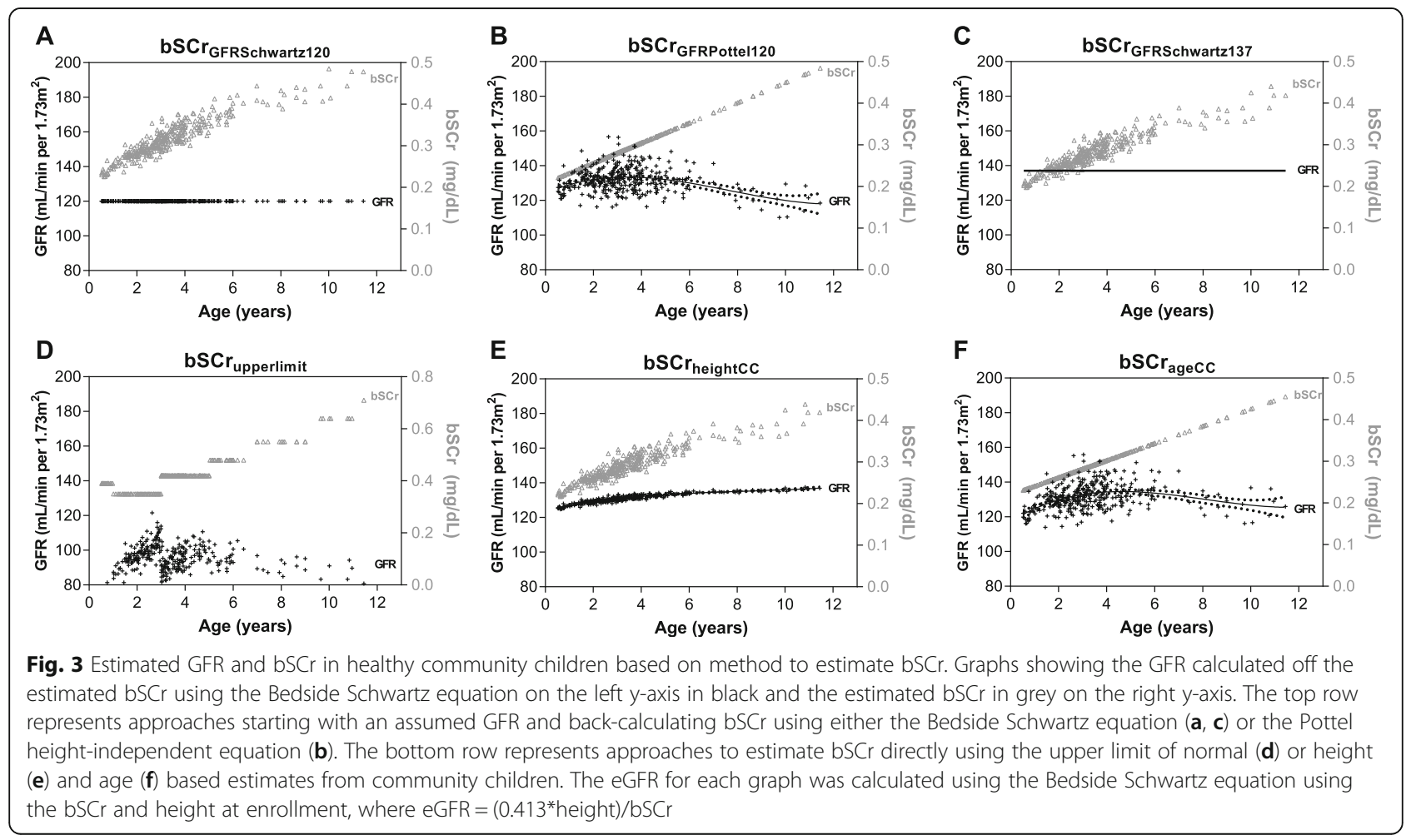


Table 2 Agreement between measured and estimated serum creatinine in community children

\begin{tabular}{|c|c|c|c|c|c|c|c|}
\hline & \multirow{3}{*}{$\begin{array}{l}\text { Measured } \\
\mathrm{SCr}\end{array}$} & \multicolumn{6}{|l|}{ Estimated } \\
\hline & & \multicolumn{3}{|c|}{ bSCr back-calculated from GFR } & \multicolumn{3}{|c|}{ bSCr estimated directly } \\
\hline & & $\begin{array}{l}\mathrm{bSCr}_{\text {GFRSchwartz120 }} \\
\text { (reference) }\end{array}$ & $\mathrm{bSCr}_{\mathrm{GFRPottel} 120}$ & bSCr $r_{\text {GFRSchwartz137 }}$ & $\mathrm{bSCr}_{\text {upperlimit }}$ & bSCr $_{\text {heightcc }}$ & $\mathrm{bSCr}_{\text {agecc }}$ \\
\hline Mean (SD) (mg/dL) & $0.29(0.08)$ & $0.31(0.05)$ & $0.29(0.05)$ & $0.28(0.04)$ & $0.40(0.06)$ & $0.29(0.04)$ & $0.29(0.04)$ \\
\hline Median (IQR) (mg/dL) & $0.28(0.23,0.33)$ & $0.31(0.28,0.34)$ & $0.28(0.26,0.30)$ & $0.27(0.25,0.30)$ & $0.39(0.35,0.42)$ & $0.28(0.26,0.31)$ & $0.28(0.26,0.30)$ \\
\hline Wilcoxon $^{\mathrm{a}}$ & - & $* * *$ & NS & NS & $* * *$ & NS & NS \\
\hline Min, $\max (\mathrm{mg} / \mathrm{dL})$ & $0.19,0.56$ & $0.23,0.34$ & $0.22,0.48$ & $0.20,0.44$ & $0.35,0.71$ & $0.22,0.44$ & $0.23,0.46$ \\
\hline Correlation, $\mathrm{SCr}(r)$ & - & 0.495 & 0.485 & 0.495 & 0.407 & 0.495 & 0.485 \\
\hline Bias (mg/dL) & - & $0.025^{* * *}$ & -0.002 (NS) & $-0.014^{* * *}$ & $0.11^{* * *}$ & -0.002 (NS) & -0.002 (NS) \\
\hline Precision (mg/dL) & - & 0.07 & 0.07 & 0.07 & 0.08 & 0.07 & 0.07 \\
\hline \multicolumn{8}{|l|}{ Accuracy } \\
\hline P10, \% & - & $24 \%$ & $35 \%$ & $33 \%$ & $8 \%$ & $29 \%$ & $35 \%$ \\
\hline P30, \% & - & $71 \%$ & $79 \%$ & $82 \%$ & $33 \%$ & $80 \%$ & $78 \%$ \\
\hline Proportional Bias & - & $-0.66 \pm 0.06^{* * *}$ & $-0.70 \pm 0.06^{* * *}$ & $-0.81 \pm 0.06^{* * *}$ & $-0.35 \pm 0.07^{* * *}$ & $-0.91 \pm 0.06^{* * *}$ & $-0.88 \pm 0.06^{* * *}$ \\
\hline
\end{tabular}

Standard deviation (SD), IQR: Inter-quartile range, r: Spearman's rho, NS: Not significant, ${ }^{*} p<0.05,{ }^{* *} p<0.001,{ }^{* * *} p<0.0001$

ailcoxon signed rank test (paired) for comparison of entire distribution with measured creatinine

Bias: mean difference between estimated and measured creatinine. To estimate fixed bias, we compared value of the difference to a value of 0 using a one sample t-test

Precision: one standard deviation of the Bias

Proportional bias: the slope of the regression line of the differences between estimated and measured creatinine against the average of estimated and measured creatinine. A slope of 0 means no proportional bias

Accuracy reflects the percentage of estimated $\mathrm{SCr}$ within 10 or $30 \%$ of the measured $\mathrm{SCr}$, where accuracy $=[(\mathrm{measured} \mathrm{SCr}$ - estimated $\mathrm{SCr}) / \mathrm{measured} \mathrm{SCr}] * 100$

$P$ value is the significance of the deviation of the slope from $0 .{ }^{* * *} p<0.0001$

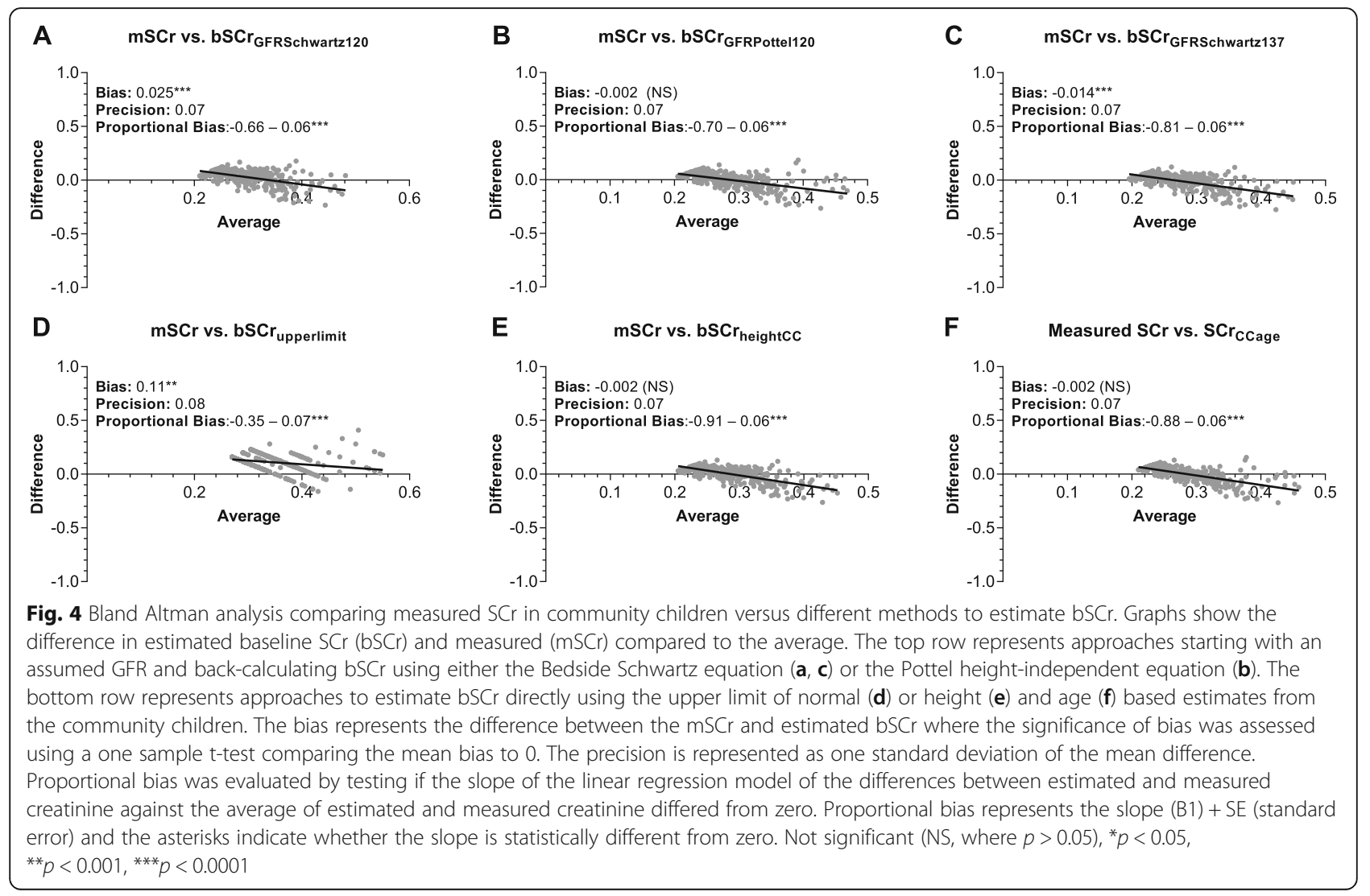


Table 3 Estimates of bSCr and eGFR in healthy community children based on age at enrollment

\begin{tabular}{|c|c|c|c|c|c|c|c|c|c|c|}
\hline & \multicolumn{2}{|c|}{$\begin{array}{l}\text { Age }<1 \text { years } \\
(n=18)\end{array}$} & \multicolumn{2}{|c|}{$\begin{array}{l}\text { Age } 1 \text { to }<2 \text { years } \\
(n=46)\end{array}$} & \multicolumn{2}{|c|}{$\begin{array}{l}\text { Age } 2 \text { to }<5 \text { years } \\
(n=192)\end{array}$} & \multicolumn{2}{|c|}{$\begin{array}{l}\text { Age } \geq 5 \text { years } \\
(n=33)\end{array}$} & \multicolumn{2}{|c|}{$P$ value $^{1}$} \\
\hline & $\mathrm{bSCr}$ & eGFR & $\mathrm{bSCr}$ & eGFR & $\mathrm{bSCr}$ & eGFR & $\mathrm{bSCr}$ & eGFR & $\mathrm{SCr}$ & eGFR \\
\hline \multicolumn{11}{|l|}{ Reference } \\
\hline Measured SCr & $0.23(0.04)$ & $127.3(20.8)$ & $0.25(0.06)$ & $135.9(29.0)$ & $0.29(0.07)$ & $138.2(30.8)$ & $0.37(0.08)$ & $136.0(28.7)$ & $<0.001$ & 0.484 \\
\hline \multicolumn{11}{|c|}{ SCr estimated by back calculating from an assumed GFR } \\
\hline bSCr GFRSChwartz120 $0^{a}$ & $0.24(0.01)$ & $120(0.0)$ & $0.27(0.01)$ & $120(0.0)$ & $0.32(0.03)$ & $120(0.0)$ & $0.41(0.04)$ & $120(0.0)$ & $<0.001$ & - \\
\hline $\mathrm{bSCr}_{\text {GFRPottel120 }}{ }^{\mathrm{b}}$ & $0.23(0.003)$ & $126.8(4.6)$ & $0.25(0.01)$ & $131.9(5.0)$ & $0.29(0.02)$ & $132.7(7.0)$ & $0.39(0.05)$ & $126.8(8.0)$ & $<0.001$ & $<0.001$ \\
\hline $\mathrm{bSCr}_{\text {GFRSchwartz137 }}{ }^{\mathrm{a}}$ & $0.21(0.009)$ & $137(0.0)$ & $0.24(0.01)$ & $137(0.0)$ & $0.28(0.02)$ & $137(0.0)$ & $0.36(0.03)$ & $137(0.0)$ & $<0.001$ & $<0.001$ \\
\hline \multicolumn{11}{|c|}{ SCr estimated directly } \\
\hline bSCr ${ }_{\text {upperlimit }}{ }^{c}$ & $0.39(0.0)$ & $73.3(3.1)$ & $0.35(0.0)$ & $92.9(4.5)$ & $0.39(0.03)$ & $97.5(6.8)$ & $0.54(0.07)$ & $90.8(7.1)$ & $<0.001$ & $<0.001$ \\
\hline bSCrccheight $^{d}$ & $0.23(0.01)$ & $125.9(0.8)$ & $0.25(0.01)$ & $128.4(0.9)$ & $0.29(0.02)$ & $131.0(1.4)$ & $0.36(0.03)$ & $134.7(1.2)$ & $<0.001$ & $<0.001$ \\
\hline bSCrccage & $0.23(0.003)$ & $121.8(4.5)$ & $0.25(0.01)$ & $128.8(5.0)$ & $0.29(0.02)$ & $132.5(7.2)$ & $0.37(0.04)$ & $131.6(7.2)$ & $<0.001$ & $<0.001$ \\
\hline
\end{tabular}

${ }^{1} P$ value calculated using ANOVA to evaluate mean differences across age categories

a Bedside Schwartz equation (eGFR $=0.413^{*}$ height $/ \mathrm{SCr}$ ) used to back calculate creatinine assuming a normal of $120 \mathrm{~mL} / \mathrm{min} / 1.73 \mathrm{~m}^{2}$ or $137 \mathrm{~mL} / \mathrm{min} / 1.73 \mathrm{~m}^{2}(\mathrm{mean}$ of the community children)

${ }^{\mathrm{b}}$ Pottel equation ( $\mathrm{eGFR}=107.3 /(\mathrm{SCr} / \mathrm{Q})$, where $\mathrm{Q}=0.0270^{*} \mathrm{age}+0.2329$ ) used to back calculate creatinine assuming a normal of $120 \mathrm{~mL} / \mathrm{min}$ per $1.73 \mathrm{~m}^{2}$

'Upper limit using Ceriotti et al., Clin Chem 2008 54:3

dLinear regression model of height vs. creatinine using healthy community children to estimate baseline creatinine from model

e Linear regression model of age vs. creatinine using healthy community children to estimate baseline creatinine from model

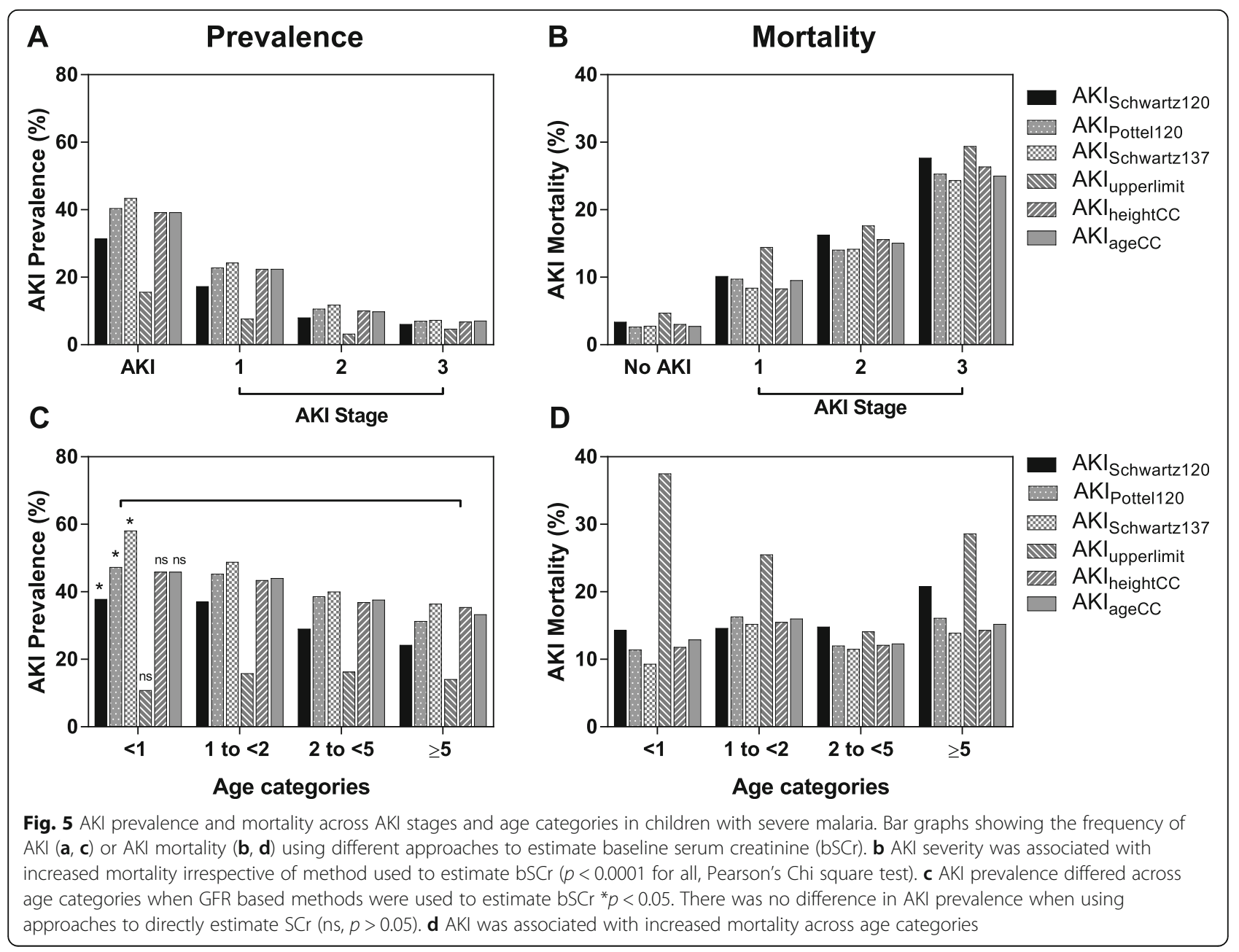


community children were as follows: i) $\mathrm{AKI}_{\mathrm{GFRPottel} 120}$, 40.4\% (95\% CI 37.5-43.3); ii) $\mathrm{AKI}_{\text {heightCC }}$ 39.2\% (95\% CI 36.3-42.2); iii) $\mathrm{AKI}_{\mathrm{ageCC}}, 39.2 \%$ (95\% CI 36.3-42.2). Using the Bedside Schwartz equation assuming an eGFR of $120 \mathrm{~mL} / \mathrm{min}$ per $1.73 \mathrm{~m}^{2}$ underestimated AKI in this setting missing over $20 \%$ of AKI identified using population-based approaches $\left(\mathrm{AKI}_{\text {heightCC }}, \mathrm{AKI}_{\text {ageCC }}\right)$. All approaches based on a fixed eGFR estimate $\left(\mathrm{AKI}_{\mathrm{GFRSch}}\right.$ wartz120, $\left.\mathrm{AKI}_{\mathrm{GFRPottel120}}, \mathrm{AKI}_{\mathrm{GFRSchwartz137}}\right)$ resulted in an increase in AKI prevalence in infants aged 6 months to 1 year compared to the older age groups (Fig. $5 \mathrm{c}$ ).

The Pottel equation had the highest area under the ROC curve, along with the highest sensitivity to predict mortality at $77.6 \%$, and the highest risk ratio at 5.13 (95\% CI 3.03-8.68) adjusting for child age and sex (Table 4). Mortality in children diagnosed with AKI using the Pottel equation was $13.6 \%$ overall and increased across AKI stages from 9.8\% in stage 1 AKI, $14.0 \%$ in stage $2 \mathrm{AKI}$ and $25.3 \%$ in stage $3 \mathrm{AKI}$. The relationship between AKI and mortality was consistent across age groups with change in mortality across age groups (Fig. 5d).

\section{Discussion}

In the present study we evaluated six different approaches to estimate bSCr in Ugandan children. In this undernourished population of Ugandan children, assuming a normal GFR of $120 \mathrm{~mL} / \mathrm{min}$ per $1.73 \mathrm{~m}^{2}$ to calculate estimated bSCr underestimated AKI but retained good sensitivity to predict mortality. Of published methods, the Pottel height-independent approach to estimate bSCr in our population of lean Ugandan children was the most accurate and had the least bias. Further, the Pottel height-independent equation showed the strongest relationship with mortality in children with severe malaria.

There is a physiological increase in GFR from birth to age 2 [32]. A number of pediatric studies suggest using age-based normative eGFR values in children $<2$ years of age to account for the physiological changes in GFR in this age group [7, 8]. In the present study we observed an increase in eGFR across age groups, but the eGFR was greater than $120 \mathrm{~mL} / \mathrm{min}$ per $1.73 \mathrm{~m}^{2}$ across all age groups, including infants, suggesting that using normative eGFR values in children $<2$ years of age may not be as applicable in Ugandan children. This emphasizes the importance of nutritional status and body habitus when selecting methods to estimate bSCr and the need for evaluating and validating a range of equations. Efforts are underway to evaluate eGFR equations in adults across sub-Saharan Africa [15], and parallel efforts in children would be advantageous to better understand how measured GFR and estimated bSCr relate in this setting.

Our results are consistent with a high prevalence of AKI in children with severe malaria irrespective of age [25], and challenge the paradigm that AKI in severe malaria is more frequent in older children and adults [18]. The children in this study were 12 and under. Whether our results apply to older children who are more likely to have undergone puberty will need to be determined in future studies. We demonstrate that AKI is common across all age groups. There were no differences in mortality across age groups in this pediatric population. Larger studies will be needed to evaluate whether there are age-related differences in susceptibility to AKI and whether there are age-related differences in outcomes in pediatric populations.

The three approaches of back-calculating estimated bSCr based on a fixed eGFR showed differences in AKI prevalence across age groups with the highest prevalence seen in infants and the lowest prevalence observed in children $<5$ years of age (Fig. 5 c, Table S2). When comparing approaches of estimating bSCr in community children, bSCr estimates were closest to the measured value in infants. All approaches to estimate bSCr in the study population had a significant proportional bias as seen by a positive slope on the Bland-Altman plots in Fig. 4, and all models except the upper limit of normal underestimated bSCr in older children. As such, the prevalence of AKI in infants is likely accurate, but AKI may be underestimated in older children. In the present

Table 4 Relationship between AKI and mortality

\begin{tabular}{|c|c|c|c|c|c|c|c|c|}
\hline \multirow{2}{*}{$\begin{array}{l}\text { AKI } \\
\text { Classification }\end{array}$} & \multirow{2}{*}{$\begin{array}{l}\text { Mortality } \\
\text { no AKI } \\
\text { N (\%) }\end{array}$} & \multirow{2}{*}{$\begin{array}{l}\text { Mortality } \\
\text { AKI } \\
\text { N (\%) }\end{array}$} & \multirow{2}{*}{$\begin{array}{l}\text { Risk Ratio } \\
(95 \% \mathrm{Cl})\end{array}$} & \multicolumn{2}{|c|}{ Model Fit } & \multirow{2}{*}{$\begin{array}{l}\text { AKI Area } \\
\text { under ROC }\end{array}$} & \multirow[b]{2}{*}{ Sensitivity } & \multirow[b]{2}{*}{ Specificity } \\
\hline & & & & AIC & $\mathrm{BIC}$ & & & \\
\hline AKI $\left.\right|_{\text {Schwartz120 }}$ & $25(3.4)$ & $51(15.1)$ & $4.41(2.78,7.00)$ & 0.473 & -6990.3 & $0.69(0.64,0.75)$ & $67.1 \%$ & $71.3 \%$ \\
\hline AKI pottel120 & $17(2.7)$ & 59 (13.6) & $5.13(3.03,8.68)$ & 0.469 & -6994.0 & $0.70(0.65,0.75)$ & $77.6 \%$ & $62.4 \%$ \\
\hline AKI $\left.\right|_{\text {Schwartz137 }}$ & $17(2.8)$ & 59 (12.6) & $4.50(2.66,7.62)$ & 0.477 & -6986.2 & $0.68(0.63,0.73)$ & $77.6 \%$ & $59.2 \%$ \\
\hline AKl $\left.\right|_{\text {upperlimit }}$ & $43(4.7)$ & 33 (19.6) & $4.17(2.74,6.36)$ & 0.479 & -6984.1 & $0.65(0.59,0.71)$ & $43.4 \%$ & $86.5 \%$ \\
\hline AKI heightCC & $20(3.1)$ & $56(13.3)$ & $4.28(2.61,7.03)$ & 0.477 & -6986.3 & $0.69(0.63,0.74)$ & $73.7 \%$ & $63.4 \%$ \\
\hline$A K l_{\text {agecc }}$ & $18(2.8)$ & $58(13.7)$ & $4.99(2.98,8.34)$ & 0.470 & -6993.6 & $0.70(0.65,0.75)$ & $76.3 \%$ & $63.5 \%$ \\
\hline
\end{tabular}

Risk ratio estimated using a generalized linear model with binomial family and log link adjusting for age and sex 
study the majority of the community children were $<5$ years of age. A larger population of children $>5$ years and adolescents are needed to establish norms across the pediatric age spectrum in this setting.

Accurate assessment of height in critically ill populations can be challenging, and appropriate measurement tools are not always available in resource-constrained settings. This study was able to assess the reliability of height measures over time using mixed effects models adjusting for child age and sex to correct individual-level outliers as described [24, 25]. We identified several heights that required adjustment based on the child's individual growth trajectory or the mean height-for-age score for the population. Given potential limitations in obtaining accurate height measurements in critically ill populations, including infection-control concerns in certain high-risk populations (e.g. Ebolavirus [33]), the validation of age-based approaches to estimate bSCr in hospitalized patients in LMIC settings is essential.

The Pottel equation was derived from a large hospital database of normal creatinine in Belgian children and differs from the Bedside Schwartz equation, which was developed in children with chronic kidney disease. The height independent Pottel equation (eGFR $=107.3 /(\mathrm{Scr} /$ Q) uses age-based norms of creatinine defined by Q. Updates to the height-independent equation have been suggested to modify the calculation of $\mathrm{Q}$ by sex and age and extend it into adolescence and early adulthood (Hoste(age) [34]). The updated Hoste(age) equation and use of $Q$ alone led to overestimation of creatinine in our study population. Thus, the original Pottel equation assuming a normal eGFR of $120 \mathrm{~mL} / \mathrm{min}$ per $1.73 \mathrm{~m}^{2}$ was the most appropriate in our population and closely resembled the linear regression estimates of $\mathrm{bSCr}_{\text {ageCC }}$ derived using measured values from community children. With the advantage of not requiring a height measurement, the Pottel age-based equation is more suitable for large population-based studies.

In this study we included the upper limit of normal to estimate AKI as this approach was used in the largest prospective study of AKI in Ugandan children that was conducted in 2055 hospitalized children aged $0-15$ years at Mulago National Referral Hospital [28]. The prevalence of AKI in the study by Imani et al., was $13.5 \%$ overall, and was $5.4 \%$ in children with malaria [28]. In the present study the prevalence of AKI in children that met WHO severe malaria criteria on admission using the upper limit of normal was nearly three-fold higher at $15.6 \%$ compared to $5.4 \%$ in the study by Imani et al., and $40.4 \%$ using our recommended approach of $\mathrm{AKI}_{\text {Pottel120 }}$. Therefore, we estimate that the prevalence of AKI in the study by Imani et al., would likely be between 27.2$35.0 \%$ using more sensitive approaches of $\mathrm{bSCr}_{\mathrm{GFRSchwartz120}}$ or $\mathrm{bSCr}_{\mathrm{GFRPottel120}}$ respectively. AKI is a well-established risk factor for mortality in critically ill populations. The ideal AKI definition should be sensitive as small increases in creatinine are associated with increased mortality [5, 10, 35]. Further, AKI is a risk factor for the long-term development of chronic kidney disease (CKD) in both adult and pediatric populations [25, 3641]. In Ugandan severe malaria survivors AKI is a risk factor for long-term neurocognitive impairment and behavioral problems [25, 42]. The use of sensitive AKI definitions is important to identify children at risk of inhospital mortality, but also to identify children at risk for post-discharge morbidity (e.g. repeated admissions, chronic kidney disease, cardiovascular disease), and mortality.

There were a number of limitations in this study. First, we were unable to directly measure GFR in the studied population using methodology such as iohexol clearance and had to rely on using equations developed in other contexts. None of the children with severe malaria had a known bSCr, so we had to evaluate approaches to estimate bSCr using healthy community children. As the methods to estimate bSCR were derived from the community children, this likely contributed to the good performance of the approaches. Additional prospective studies are required to externally validate these approaches in an independent cohort of Ugandan children. We were unable to rule out congenital malformations of the genitourinary system in the healthy children, so it is possible that children with clinically silent kidney disease were included. However, children with a history of chronic disease were not eligible for the study, and two children with evidence of underlying kidney disease were excluded from the study. It is possible some of the children with severe malaria had underlying kidney disease that made them susceptible to AKI and severe disease. However, as malaria is an acute febrile illness that typically occurs in previously healthy children, we expect the number of children with underlying kidney disease in the severe malaria group to be low. None of the community children had HIV-infection or a history of infection requiring medical attention in the 4 weeks prior to enrollment.

There are a number of strengths in this study. We were able to combine two cohorts of healthy community children and children with severe malaria to assess normal renal function in a relatively large population of Ugandan children. As children were followed longitudinally we were able to use the child's growth trajectory to identify height outliers. We were also able to assess AKI in a population of children with severe malaria from the same community as the healthy children. As the study included children from 6 months of age, we were able to evaluate methods to estimate bSCr during a period of physiological changes in GFR. All children were 
genotyped for sickle cell anemia and we were able to evaluate whether there were differences in $\mathrm{SCr}$ in community children with sickle cell trait, as there is evidence that sickle cell trait may lead to more subtle changes in kidney function [43] and increases risk of chronic kidney disease in some [44, 45], but not all populations [46]. Children with sickle cell disease have hyperfiltration [47-50] and increased tubular secretion of creatinine $[47,51]$ contributing to lower bSCr levels. Additional research is needed to understand how sickle cell trait and sickle cell disease modifies normal kidney function, affects bSCr estimation, and whether sickle cell anemia increases the risk of severe malaria-associated AKI in the population.

\section{Conclusion}

AKI is an important complication in hospitalized children and is diagnosed based on a change in creatinine from known or estimated bSCr. As AKI in LMIC is often community-acquired, there is an urgent need to identify the most appropriate approach to estimate bSCr in low-income settings. We considered both heightdependent and height-independent age-based approaches to estimate bSCr, and conclude that the Pottelheight independent GFR estimating equation represents the most appropriate equation for Ugandan children and represents a promising approach to adapt to other LMIC settings.

\section{Supplementary information}

Supplementary information accompanies this paper at https://doi.org/10. 1186/s12882-020-02076-1.

Additional file 1 Figure S1. Creatinine-for-height and creatinine-forage curves for healthy community children. Table S1. Distribution of AKI and AKI severity using different methods of estimating baseline $\mathrm{SCr}$ in severe malaria. Table S2. AKI prevalence $(95 \% \mathrm{Cl})$ in children with severe malaria based on age category.

\section{Abbreviations}

AIC: Akaike Information Criterion; AKI: Acute Kidney Injury; BIC: Bayesian information criterion; BMl: Body mass index; bSCr: Baseline serum creatinine; Cl: Confidence Interval; GFR: Glomerular filtration rate; HIV: Human immunodeficiency virus; KDIGO: Kidney Disease: Improving Global Outcomes; LMIC: Low- and middle income country; RR: Risk ratio; ROC: Receiver operator characteristic; WHO: World Health Organization

\section{Acknowledgments}

We thank the children and their parents who participated in this study, the study team for their dedicated effort in treating the children and collecting the data.

\section{Authors' contributions}

$A B, M C S$ and ALS participated in the study design, analysis and critical review of the manuscript. RN, ROO were involved in study participant recruitment, data acquisition, and critically reviewed the manuscript. ESPN participated in the study design, data cleaning and critical review of the manuscript. JMS conducted the data analysis. CCJ participated in study design, and supervision. ALC conceived of the study, performed the analysis and wrote the first draft of the manuscript. All authors reviewed and approved the submitted manuscript and agree to be personally accountable for their own contributions and to ensure that questions related to the accuracy and integrity of any part of the work.

\section{Funding}

This work was supported by the National Institutes of Health (NIH) National Institute of Neurological Disorders and Stroke (grant R01NS055349 to CCJ) and the Fogarty International Center (D43 NS078280 to CCJ), and a Ralph W. and Grace M. Showalter research award to ALC.

Availability of data and materials

The datasets used and/or analyzed during the current study are available from the corresponding author on reasonable request.

\section{Ethics approval and consent to participate}

Written informed consent was obtained from parents/guardians of study participants. Ethical approval was granted by the Institutional Review Boards at Makerere University School of Medicine (Cohort \#1, Ref: 2008-033, date approved: April 7th 2008; Cohort \#2, Ref: 2013-141, date approved: September 23rd 2014), the University of Minnesota (Cohort \# 1, Ref: 0802 M27022, date approved: March 31st 2008; Cohort \#2, Ref: 1309 M42501, date approved: September 23, 2013) and subsequently moved to Indiana University (Cohort \# 2, Ref: 1412213778, date approved: January 20th, 2015). The studies were approved by the Uganda National Council for Science and Technology (Cohort \#1, Ref: HS 432, date approved: May 16th 2008; Cohort \#2, Ref: HS1522, date approved: May 12th 2013).

\section{Consent for publication}

Not applicable.

\section{Competing interests}

The authors report no competing interests.

\section{Author details}

${ }^{1}$ Child Health and Development Center, Makerere University College of Health Sciences, Kampala, Uganda. ${ }^{2}$ Department of Pediatrics, Division of Nephrology, Indiana University School of Medicine, Indianapolis, Indiana, USA. ${ }^{3}$ Department of Paediatrics and Child Health, Makerere University College of Health Sciences, Kampala, Uganda. ${ }^{4}$ Developmental Behavioral Pediatrics, University of Washington, Seattle, Washington, USA. ${ }^{5}$ Department of Epidemiology and Biostatistics, Makerere University School of Public Health, Kampala, Uganda. ${ }^{6}$ Department of Pediatrics, Ryan White Center for Pediatric Infectious Disease and Global Health, Indiana University School of Medicine, 1044 W. Walnut St., Indianapolis, IN 46202, USA.

Received: 16 June 2020 Accepted: 18 September 2020

Published online: 29 September 2020

\section{References}

1. Mehta RL, Cerda J, Burdmann EA, Tonelli M, Garcia-Garcia G, Jha V, Susantitaphong P, Rocco M, Vanholder R, Sever MS, et al. International Society of Nephrology's 0by25 initiative for acute kidney injury (zero preventable deaths by 2025): a human rights case for nephrology. Lancet. 2015;385(9987):2616-43.

2. Olowu WA, Niang A, Osafo C, Ashuntantang G, Arogundade FA, Porter J, Naicker S, Luyckx VA. Outcomes of acute kidney injury in children and adults in sub-Saharan Africa: a systematic review. Lancet Glob Health. 2016; 4(4):e242-50.

3. Mehta RL, Burdmann EA, Cerda J, Feehally J, Finkelstein F, Garcia-Garcia G, Godin M, Jha V, Lameire NH, Levin NW, et al. Recognition and management of acute kidney injury in the International Society of Nephrology 0 by 25 global snapshot: a multinational cross-sectional study. Lancet. 2016; 387(10032):2017-25.

4. Conroy AL, Hawkes M, Elphinstone RE, Morgan C, Hermann L, Barker KR, Namasopo S, Opoka RO, John CC, Liles WC, et al. Acute kidney injury is common in pediatric severe malaria and is associated with increased mortality. Open Forum Infect Dis. 2016;3(2):ofw046.

5. KDIGO. KDIGO clinical practice guideline for acute kidney injury. Kidney Int Suppl. 2012;2(1):1-138. 
6. Zappitelli M, Parikh CR, Akcan-Arikan A, Washburn KK, Moffett BS, Goldstein SL. Ascertainment and epidemiology of acute kidney injury varies with definition interpretation. Clin J Am Soc Nephrol. 2008;3(4):948-54.

7. Alkandari O, Eddington KA, Hyder A, Gauvin F, Ducruet T, Gottesman R, Phan V, Zappitelli M. Acute kidney injury is an independent risk factor for pediatric intensive care unit mortality, longer length of stay and prolonged mechanical ventilation in critically ill children: a two-center retrospective cohort study. Crit Care. 2011;15(3):R146.

8. Hessey E, Ali R, Dorais M, Morissette G, Pizzi M, Rink N, Jouvet P, Lacroix J, Phan V, Zappitelli M. Evaluation of height-dependent and heightindependent methods of estimating baseline serum creatinine in critically ill children. Pediatr Nephrol (Berlin, Germany). 2017;32(10):1953-62.

9. Basu RK, Kaddourah A, Terrell T, Mottes T, Arnold P, Jacobs J, Andringa J, Goldstein SL. Prospective pediatric AKIRG: assessment of worldwide acute kidney injury, renal angina and epidemiology in critically ill children (AWAR E): study protocol for a prospective observational study. BMC Nephrol. 2015; $16: 24$

10. Kaddourah A, Basu RK, Bagshaw SM, Goldstein SL, Investigators A. Epidemiology of acute kidney injury in critically ill children and young adults. N Engl J Med. 2017;376(1):11-20.

11. Klahr S, Alleyne GA. Effects of chronic protein-calorie malnutrition on the kidney. Kidney Int. 1973;3(3):129-41.

12. Baxmann AC, Ahmed MS, Marques NC, Menon VB, Pereira AB, Kirsztajn GM, Heilberg IP. Influence of muscle mass and physical activity on serum and urinary creatinine and serum cystatin C. Clin J Am Soc Nephrol. 2008;3(2): 348-54.

13. George JA, Brandenburg JT, Fabian J, Crowther NJ, Agongo G, Alberts M, Ali S, Asiki G, Boua PR, Gomez-Olive FX, et al. Kidney damage and associated risk factors in rural and urban sub-Saharan Africa (AWl-gen): a cross-sectional population study. Lancet Glob Health. 2019;7(12): e1632-43.

14. Fabian J, George JA, Etheredge HR, van Deventer M, Kalyesubula R, Wade AN, Tomlinson LA, Tollman S, Naicker S. Methods and reporting of kidney function: a systematic review of studies from sub-Saharan Africa. Clin Kidney J. 2019;12(6):778-87.

15. Kalyesubula R, Fabian J, Nakanga W, Newton R, Ssebunnya B, Prynn J, George J, Wade AN, Seeley J, Nitsch D, et al. How to estimate glomerular filtration rate in sub-Saharan Africa: design and methods of the African research into kidney diseases (ARK) study. BMC Nephrol. 2020;21(1):20.

16. Muiru AN, Charlebois ED, Balzer LB, Kwarisiima D, Elly A, Black D, Okiror S, Kabami J, Atukunda M, Snyman K, et al. The epidemiology of chronic kidney disease (CKD) in rural East Africa: a population-based study. PLoS One. 2020; 15(3):e0229649.

17. Kayange NM, Smart LR, Tallman JE, Chu EY, Fitzgerald DW, Pain KJ, Peck RN. Kidney disease among children in sub-Saharan Africa: systematic review. Pediatr Res. 2015;77(2):272-81.

18. World Health Organization. Severe Malaria. Tropical Med Int Health. 2014;19: 7-131.

19. Bangirana P, Opoka RO, Boivin MJ, Idro R, Hodges JS, Romero RA, Shapiro E, John CC. Severe malarial anemia is associated with long-term neurocognitive impairment. Clin Infect Dis. 2014:59(3):336-44.

20. Group WMGRS. WHO child growth standards: length/height-for-age, weight-for-age, weight-for-length, weight-for-height and body mass indexfor-age: methods and development. Geneva: World Health Organization; 2006. p. 312

21. de Onis M, Onyango AW, Borghi E, Siyam A, Nishida C, Siekmann J. Development of a WHO growth reference for school-aged children and adolescents. Bull World Health Organ. 2007;85(9):660-7.

22. Opoka RO, Bangirana P, Idro R, Shabani E, Namazzi R, John CC. Lack of mortality in 22 children with sickle cell anemia and severe malarial anemia. Pediatr Blood Cancer. 2018;65(1). https://doi.org/10.1002/pbc.26745.

23. Flynn JT, Kaelber DC, Baker-Smith CM, Blowey D, Carroll AE, Daniels SR, de Ferranti SD, Dionne JM, Falkner B, Flinn SK, et al. Clinical practice guideline for screening and Management of High Blood Pressure in children and adolescents. Pediatrics. 2017;140(3):e20171904.

24. Welch C, Petersen I, Walters K, Morris RW, Nazareth I, Kalaitzaki E, White IR, Marston L, Carpenter J. Two-stage method to remove population- and individual-level outliers from longitudinal data in a primary care database. Pharmacoepidemiol Drug Saf. 2012;21(7):725-32.

25. Conroy AL, Opoka RO, Bangirana P, Idro R, Ssenkusu JM, Datta D, Hodges JS, Morgan C, John CC. Acute kidney injury is associated with impaired cognition and chronic kidney disease in a prospective cohort of children with severe malaria. BMC Med. 2019;17(1):98.

26. Schwartz GJ, Munoz A, Schneider MF, Mak RH, Kaskel F, Warady BA, Furth SL. New equations to estimate GFR in children with CKD. J Am Soc Nephrol. 2009;20(3):629-37.

27. Pottel H, Hoste L, Martens F. A simple height-independent equation for estimating glomerular filtration rate in children. Pediatr Nephrol (Berlin, Germany). 2012;27:973-9

28. Imani PD, Odiit A, Hingorani SR, Weiss NS, Eddy AA. Acute kidney injury and its association with in-hospital mortality among children with acute infections. Pediatr Nephrol (Berlin, Germany). 2013;28(11):2199-206.

29. Ludbrook J. Confidence in Altman-bland plots: a critical review of the method of differences. Clin Exp Pharmacol Physiol. 2010;37(2):143-9.

30. Hari P, Bagga A, Mahajan P, Lakshmy R. Effect of malnutrition on serum creatinine and cystatin C levels. Pediatr Nephrol (Berlin, Germany). 2007; 22(10):1757-61.

31. Ndeezi G, Kiyaga C, Hernandez AG, Munube D, Howard TA, Ssewanyana I, Nsungwa J, Kiguli S, Ndugwa CM, Ware RE, et al. Burden of sickle cell trait and disease in the Uganda sickle surveillance study (US3): a cross-sectional study. Lancet Glob Health. 2016;4(3):e195-200.

32. Piepsz $\mathrm{A}$, Tondeur $\mathrm{M}$, Ham $\mathrm{H}$. Revisiting normal $51 \mathrm{Cr}$ ethylenediaminetetraacetic acid clearance values in children. Eur J Nucl Med Mol Imaging. 2006:33(12):1477-82.

33. Kasereka MC, Ericson AD, Conroy AL, Tumba L, Mwesha OD, Hawkes MT. Prior vaccination with recombinant vesicular stomatitis virus - Zaire Ebolavirus vaccine is associated with improved survival among patients with Ebolavirus infection. Vaccine. 2020;38(14):3003-7.

34. Hoste L, Dubourg L, Selistre L, De Souza VC, Ranchin B, Hadj-Aissa A, Cochat $P$, Martens $F$, Pottel $H$. A new equation to estimate the glomerular filtration rate in children, adolescents and young adults. Nephrol Dial Transplant. 2014;29(5):1082-91.

35. Hoste EAJ, Clermont G, Kersten A, Venkataraman R, Angus DC, De Bacquer $D$, Kellum JA. RIFLE criteria for acute kidney injury is associated with hospital mortality in critically ill patients: a cohort analysis. Crit Care. 2006;10:R73.

36. Horkan CM, Purtle SW, Mendu ML, Moromizato T, Gibbons FK, Christopher KB. The association of acute kidney injury in the critically ill and postdischarge outcomes: a cohort study*. Crit Care Med. 2015;43(2):354-64.

37. Mammen C, Al Abbas A, Skippen P, Nadel H, Levine D, Collet JP, Matsell DG. Long-term risk of CKD in children surviving episodes of acute kidney injury in the intensive care unit: a prospective cohort study. Am J Kidney Dis. 2012;59(4):523-30

38. Jones J, Holmen J, De Graauw J, Jovanovich A, Thornton S, Chonchol M Association of complete recovery from acute kidney injury with incident CKD stage 3 and all-cause mortality. Am J Kidney Dis. 2012;60(3):402-8.

39. Heung M, Chawla LS. Predicting progression to chronic kidney disease after recovery from acute kidney injury. Curr Opin Nephrol Hypertens. 2012;21(6): 628-34

40. Coca SG, Singanamala S, Parikh CR. Chronic kidney disease after acute kidney injury: a systematic review and meta-analysis. Kidney Int. 2012;81(5): 442-8.

41. Kellum JA, Sileanu FE, Bihorac A, Hoste EA, Chawla LS. Recovery after acute kidney injury. Am J Respir Crit Care Med. 2017;195(6):784-91.

42. Hickson MR, Conroy AL, Bangirana P, Opoka RO, Idro R, Ssenkusu JM, John CC. Acute kidney injury in Ugandan children with severe malaria is associated with long-term behavioral problems. PLoS One. 2019;14(12): e0226405.

43. Nath KA, Hebbel RP. Sickle cell disease: renal manifestations and mechanisms. Nat Rev Nephrol. 2015;11(3):161-71.

44. Naik RP, Derebail VK, Grams ME, Franceschini N, Auer PL, Peloso GM, Young BA, Lettre G, Peralta CA, Katz R, et al. Association of sickle cell trait with chronic kidney disease and albuminuria in African Americans. JAMA. 2014; 312(20):2115-25.

45. Dueker ND, Della-Morte D, Rundek T, Sacco RL, Blanton SH. Sickle cell trait and renal function in Hispanics in the United States: the northern Manhattan study. Ethn Dis. 2017;27(1):11-4.

46. Akinbodewa AA, Ogunleye A, Adejumo OA, Daomi VO, Okunola O, Oluwafemi TT, Alli EO, Olalusi VO, Osho PO, Lamidi OA, et al. Study of association between sickle cell trait and renal dysfunction among young adults in south-West Nigeria. Niger J Clin Pract. 2019;22(2):201-7.

47. Scheinman Jl. Sickle cell disease and the kidney. Nat Clin Pract Nephrol. 2009;5(2):78-88. 
48. Aygun B, Mortier NA, Smeltzer MP, Hankins JS, Ware RE. Glomerular hyperfiltration and albuminuria in children with sickle cell anemia. Pediatr Nephrol (Berlin, Germany). 2011;26(8):1285-90.

49. Alvarez O, Miller ST, Wang WC, Luo Z, McCarville MB, Schwartz GJ, Thompson B, Howard T, lyer RV, Rana SR, et al. Effect of hydroxyurea treatment on renal function parameters: results from the multi-center placebo-controlled BABY HUG clinical trial for infants with sickle cell anemia. Pediatr Blood Cancer. 2012;59(4):668-74.

50. Lebensburger JD, Aban I, Pernell B, Kasztan M, Feig DI, Hilliard LM, Askenazi DJ. Hyperfiltration during early childhood precedes albuminuria in pediatric sickle cell nephropathy. Am J Hematol. 2019;94(4):417-23.

51. Allon M. Renal abnormalities in sickle cell disease. Arch Intern Med. 1990; 150(3):501-4.

\section{Publisher's Note}

Springer Nature remains neutral with regard to jurisdictional claims in published maps and institutional affiliations.

Ready to submit your research? Choose BMC and benefit from:

- fast, convenient online submission

- thorough peer review by experienced researchers in your field

- rapid publication on acceptance

- support for research data, including large and complex data types

- gold Open Access which fosters wider collaboration and increased citations

- maximum visibility for your research: over $100 \mathrm{M}$ website views per year

At BMC, research is always in progress.

Learn more biomedcentral.com/submissions 